\title{
The Efficacy of Endoscopic Exploratory Tympanotomy in Conductive Hearing Loss Patients
}

\author{
Hong Chan Kim, Wan Seok Cho, Jong Yuap Seong, \\ Eun Sun Jeon, Sung Su Lee, and Hyong-Ho Cho \\ Department of Otolaryngology-Head and Neck Surgery, Chonnam National University Medical School and \\ Chonnam National University Hospital, Gwangju, Korea
}

\section{전음성 난청 환자에서 내시경을 이용한 시험적 고실개방술의 유용성}

김홍찬 · 조완석 · 성종엽 · 전은선 · 이성수 · 조형호

전남대학교 의과대학 전남대학교병원 이비인후과학교실

Received August 5, 2016

Revised September 30, 2016

Accepted September 30, 2016

Address for correspondence

Hyong-Ho Cho, MD, PhD

Department of Otolaryngology-

Head and Neck Surgery,

Chonnam National University

Medical School and

Chonnam National

University Hospital,

42 Jebong-ro, Dong-gu,

Gwangju 61469, Korea

Tel $+82-62-220-6776$

Fax $+82-62-228-7743$

E-mailvvictocho@hanmail.net
Background and Objectives The aim of this study is to investigate the effectiveness of the endoscopic exclusive transcanalar approach for the management of conductive hearing loss. Subjects and Method This was a retrospective comparative study of 106 patients who underwent exploratory tympanotomy at Chonnam National University Hospital from January 2008 to March 2016. The subjects were classified into two groups; endoscopic tympanotomy $(\mathrm{ET}, \mathrm{n}=26)$ and microscopic tympanotomy $(\mathrm{MT}, \mathrm{n}=80)$. Demographic data, operation time, postoperative admission days, pure tone audiometric results of pre-operation and post-operation at 3 months, and hearing success rate were evaluated.

Results The mean operation time of MT $(101.7 \pm 24.8$ minutes) was longer than that of ET $(59.8 \pm 23.2$ minutes) with a statistical significance $(p<0.01)$. The mean postoperative admission days of MT $(4.4 \pm 1.3)$ was longer than that of ET $(2.0 \pm 0.6)$ with a statistical significance $(p<0.01)$. Hearing gain (air-conduction) and air-bone gap improvements were not significantly different between the groups. However, the hearing success rate of ET [partial ossicular replacement prosthesis (PORP) 85.7\%, total ossicular replacement prosthesis (TORP) 81.8\%] was significantly improved enormously compared to that of MT (PORP 62.9\%, TORP 64.3\%).

Conclusion With regards to conductive hearing loss, the endoscopic approach provided a better surgical view and less invasiveness compared with the microscopic approach. In conclusion, endoscopic exploratory tympanotomy had several advantages in operation time, admission days and hearing success rate.

Korean J Otorhinolaryngol-Head Neck Surg 2017;60(1):7-12

\section{서 론}

내시경을 이용한 중이 수술이 소개된 것은 1960년대 말로 이 당시만 해도 내시경을 이용하여 중이 수술을 하는 것에 대하여 많은 논쟁이 있었다. 특히 중이 수술을 오랫동안 수 술현미경을 이용하여 잘 수행했던 능숙한 수술 의사들에게 는 새로운 수술 방법을 배워야 하는 데에 대한 거부감이 있
으며, 내시경을 이용한 수술 방법의 필요성을 크게 느끼고 있 지 않았다. 하지만 최근 15 년간 내시경을 이용한 중이 수술 결과가 많이 발표되면서 중이 수술에 있어서 내시경의 사용 이 하나의 방식으로 정립되어 가고 있다. ${ }^{1-3)}$

초창기에 내시경의 중이 내 사용은 진주종 제거 수술에서 수술현미경을 이용하여 진주종을 제거하면서 잔존 진주종 의 확인에 내시경이 사용되거나, 고막성형술 등에 제한적으 
로 내시경이 사용되었다. 이후 내시경 장비의 발전과 수술기 법이 점차 발전하면서 내시경을 이용하여 고실성형술, 진주 종 수술, 등골 수술 및 인공와우 이식 등에도 사용됨이 보고 되었다. ${ }^{45}$ 국내에서는 2000년에 만성 중이염 및 선천성 진주 종에 대한 내시경적 수술을 처음으로 소개하여 고막의 전반
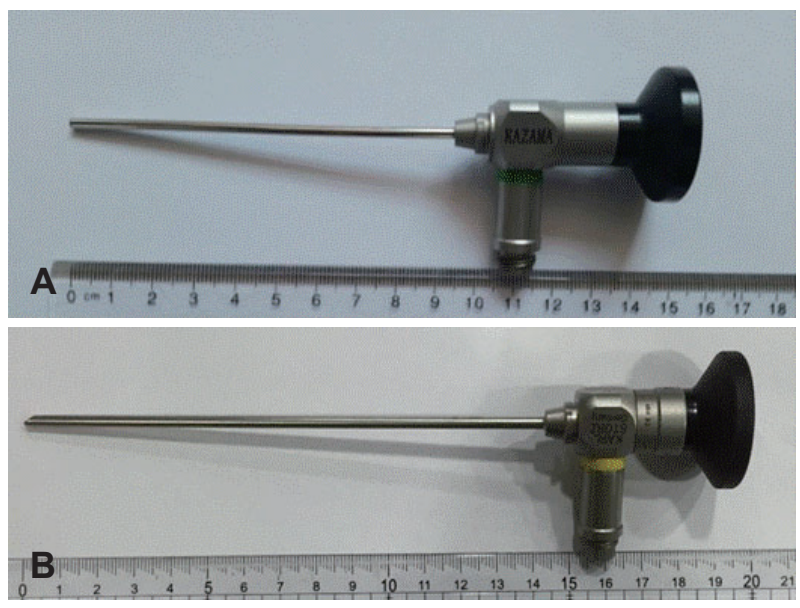

Fig. 1. Equipments used in endoscopic ear surgery. Endoscope with $9 \mathrm{~cm}$ length, $2.7 \mathrm{~mm}$ diameter, 0 degrees of angulation (A). Endoscope with $14 \mathrm{~cm}$ length, $3 \mathrm{~mm}$ diameter, 30 degrees of angulation (B).
부에 천공이 있거나 외이도가 좁은 경우, 이소골이 외이도에 가려 잘 보이지 않는 경우 등에서 최소 침습적 수술이 가능함 을 보고하였다. ${ }^{6}$

이에 저자들은 고막 천공이 없는 전도성 난청을 주소로 내 원한 환자에서 내시경을 이용한 시험적 고실개방술을 시행하 였으며, 그 결과를 수술현미경을 이용한 시험적 고실개방술과 비교·분석하여 내시경 수술의 효용성을 알아보고자 하였다.

\section{대상 및 방법}

\section{수술 기구}

중이 수술에서는 코 수술에 사용하는 내시경보다 더 가늘 고, 짧은 것을 사용하게 되는데 본원의 경우 주로 $0^{\circ} 2.7 \mathrm{~mm}$ $9 \mathrm{~cm}$ 내시경을 사용하였으며, 보조적으로 $30^{\circ} 3 \mathrm{~mm} 14 \mathrm{~cm}$ 내시경을 사용하였고, 미세 수술용 기구는 종전의 이과수술 용 기구를 그대로 사용하였다(Fig. 1).

\section{대 상}

2008년 1월부터 2016년 3월까지 전남대학교병원 이비인후 과에서 전도성 난청으로 진단된 후 한 명의 술자에 의해 시험

Table 1. Demographics of patients

\begin{tabular}{|c|c|c|c|c|}
\hline & Endoscopy & Microscopy & Total & p-value \\
\hline Patients (n) & 26 & 80 & 106 & \\
\hline Age (years) & $42.1(13-73)$ & $29.8(7-62)$ & $32.8(7-73)$ & 0.002 \\
\hline Gender (M:F) & $14: 12$ & $45: 35$ & $59: 47$ & 0.830 \\
\hline Ear $(\mathrm{Rt}: \mathrm{Lt})$ & $13: 13$ & $44: 36$ & $57: 49$ & 0.657 \\
\hline Anesthesia (general:local) & $6: 20$ & $30: 50$ & $36: 70$ & 0.177 \\
\hline Causes & & & & 0.154 \\
\hline Ossicular anomaly & 17 & 36 & 53 & \\
\hline Trauma & 0 & 9 & 9 & \\
\hline Otosclerosis & 1 & 2 & 3 & \\
\hline Post COM Op.* & 8 & 33 & 41 & \\
\hline
\end{tabular}

*when the patient had previous COM surgery without planned second stage operation in the past. COM: chronic otitis media

Fig. 2. Outcome of operation time and admission days. There was a significant difference in operation time and admission day between the two groups. We excluded transmastoid approach in operation time. *operation time is defined as the time that the patient has been in the operation room using nursing record.
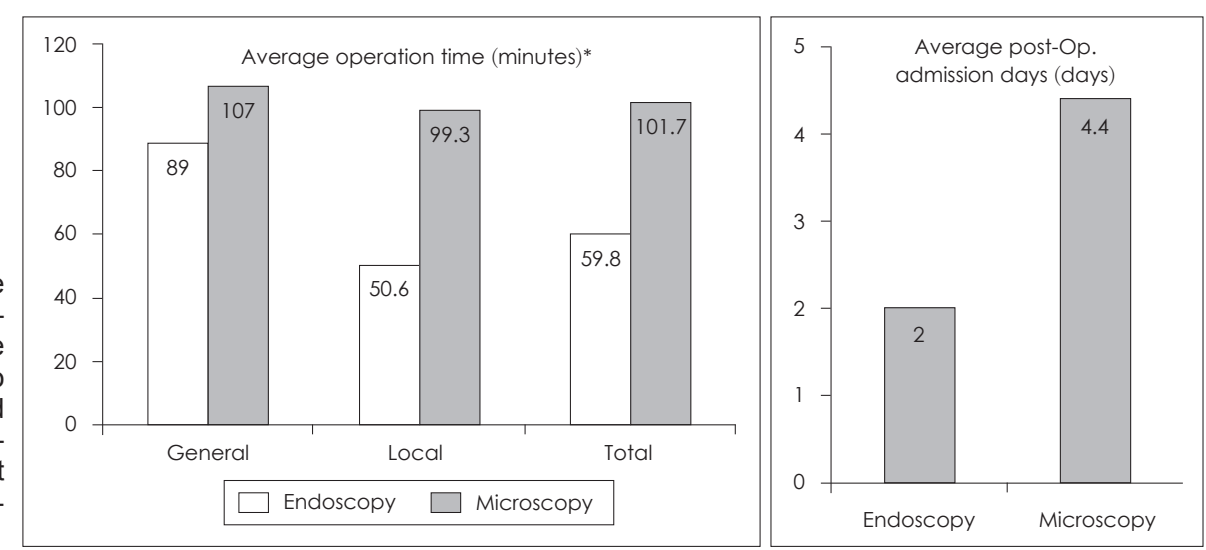
적 고실개방술을 시행한 106 명을 대상으로 하여 수술 접근법 에 따라 2군으로 분류하였다. 모두 고막 천공을 동반하지 않 는 환자로 성별분포는 남자가 59예, 여자 47예, 우측 귀 57예, 좌측 귀 49예였고 연령분포는 평균 32.8세였다(Table 1).

\section{수술 방법}

내시경하 고실개방술의 경우 경외이도 접근법으로 수술을 진행하였다. 내시경을 한 손으로 잡고 외이도에 삽입한 뒤 다 른 한 손으로 내시경을 따라 수술 기구를 집어넣어 수술을 진행하였으며 외이도 골부의 6시 및 12시 방향으로 시작하는 절개를 가하여 고막외이도피판을 만들었다. 고삭신경을 분리 하면서 고막외이도 피부판을 거상하여 고실의 주요 구조물 을 관찰하고 전도성 난청의 원인을 감별하였다. 또한 등골 상 부 구조의 존재 여부 등에 따라 부분이소골 대체재(partial ossicular replacement prosthesis, PORP) 또는 전이소골 대 체재(total ossicular replacement prosthesis, TORP)를 사용

Table 2. Demographics of approach and operative method

\begin{tabular}{lccc}
\hline & Endoscopy & Microscopy & Total \\
\hline Approach & 26 & 72 & 98 \\
Transcanal only & 0 & 8 & 8 \\
Combined (transcanal & & & \\
$\quad$ and transmastoid) & 14 & 35 & 49 \\
Op method & 11 & 28 & 39 \\
PORP & 1 & 2 & 3 \\
TORP & 0 & $15^{*}$ & 15 \\
Stapedotomy & & & \\
Etc. & & & \\
\hline
\end{tabular}

*the patients used an autologous material instead of artificial prosthesis, including incus, cartilage and bone pate. PORP: partial ossicular replacement prosthesis, TORP: total ossicular replacement prosthesis
하여 이소골성형술을 시행하였다.

현미경하 고실개방술의 경우 모든 경우에서 후이개 절개를 가한 후 고실외이도피판을 거상하여 고실을 개방한 후 이소 골의 상태를 확인하고 이소골성형술을 시행하였다. 이 중 8명 에서는 외이도가 좁거나 상고실 및 등골 부위의 시야 확보가 어려워 경유양동접근법(transmastoid approach)을 병행하여 수술을 시행하였다. 술자의 기호에 따라 이내접근법(endaural approach)은 사용하지 않았다.

\section{결과 비교}

각각의 수술 방법에 따라 수술간호 기록지에 기술된 수술 시간(현미경하 고실개방술을 시행한 경우에서 경유양동접근 법을 시행한 경우는 제외)과 수술 후 재원기간, 사용된 이소골 대체재에 따른 수술 전후 청력결과와 2006년 대한이과학회 에서 제안한 표준지침에 따른 수술 성공률그를 비교하였다.

\section{통 계}

SPSS version 19.0(SPSS Inc., Chicago, IL, USA)을 통해 독립표본 및 대응표본 $\mathrm{t}$ 검정을 사용하여 분석하였으며 $p<$ 0.05 를 통계적으로 유의하다고 정의하였다.

\section{결 과}

수술시간은 내시경하 시험적 개방술은 평균 59.8분 $(p<0.01)$ 현미경하 시험적 개방술은 평균 101.7분이 소요되었으며 술 후 재원기간은 각각 2 일 $(p<0.01)$ 과 4.4일로 유의한 차이를 보였 다(Fig. 2)

모두 고막 천공을 동반하지 않는 전도성 난청 환자로 내시
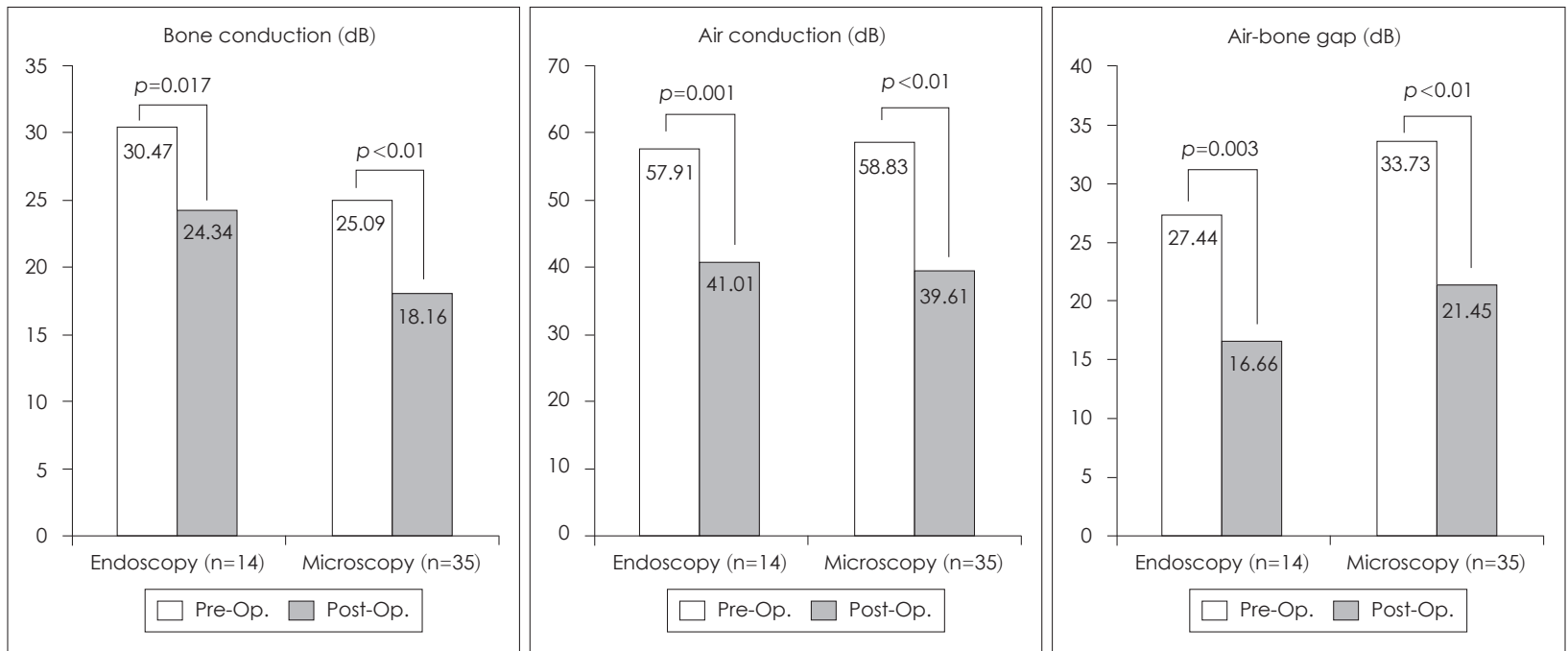

Fig. 3. Hearing results of PORP insertion. There was a significant difference in pre- and postoperative hearing result of PORP insertion within the two groups. PORP: partial ossicular replacement prosthesis. 
경군은 이소골 기형이 17 예, 이경화증 1 예, 중이염 수술 과거 력이 8예였다. 14명에서 PORP, 11명에서 TORP, 1명에서 등 골절개술(stapedotomy)를 시행하였다(Table 2).

$\mathrm{PORP}$ 를 이용하여 이소골 연쇄를 재건한 내시경군의 경우 수술 후 골도 청력(bone conduction) $(p=0.017)$, 기도 청력(air conduction)( $p=0.001)$, 기도-골도 청력차(air-bone gap)( $p=$ 0.003)가 유의하게 향상되었다(Fig. 3). 또한 본원에서 시행한 수술현미경하 시험적 고실개방술을 시행한 환자군과 비교할 시 수술 전후 기도 청력차(hearing gain) $(p=0.645)$ 및 기도-골 도 청력차(air-bone gap improvement) $(p=0.688)$ 에서 유의 한 차이가 없었다(Fig. 4).

$\mathrm{TORP}$ 를 이용하여 이소골 연쇄를 재건한 내시경군의 경우 수술 후 골도 청력 $(p=0.016)$, 기도 청력 $(p<0.01)$, 기도-골도 청 력차 $(p<0.01)$ 가 유의하게 향상되었다(Fig. 5). 또한 본원에서
시행한 수술현미경하 시험적 고실개방술을 시행한 환자군과 비교할 시 수술 전후 기도 청력차 $(p=0.834)$ 및 기도-골도 청력 차 $(p=0.979)$ 에서 유의한 차이가 없었다(Fig. 4).

2006년에 대한이과학회에서 제안한 표준지침으로 성공적 인 술 후 청력결과의 기준인 1) 술 후 기도-골도 차가 $20 \mathrm{~dB}$ 이내, 2) 술 후 청력 증진이 $15 \mathrm{~dB}$ 보다 클 때, 3) 술 후 기도역 치가 $30 \mathrm{~dB}$ 보다 작을 때의 셋 중 하나 이상을 통과하는 수 를 백분율로 표시하였을 때, PORP군의 경우 내시경하에서 는 14 명 중 12 명(85.7\%)에서 수술현미경하에서는 35 명 중 22 명(62.9\%)에서 TORP군의 경우 내시경하에서는 11 명 중 8명 (81.8\%)에서 수술현미경하에서는 28명 중 18명(64.3\%)에서 성 공적인 술 후 청력결과를 얻었다. 수술현미경과 비교하여 내 시경하에서 수술을 시행한 군에서 PORP 및 TORP 양군에서 모두 더 높은 성공률을 보였다(Table 3).
Fig. 4. Comparison of hearing enhancement and $A B G$ improvement between the two group. Hearing gain (air-conduction) and ABG improvements were not significantly different between the two groups. ABG: airbone gap, PORP: partial ossicular replacement prosthesis, TORP: total ossicular replacement prosthesis.
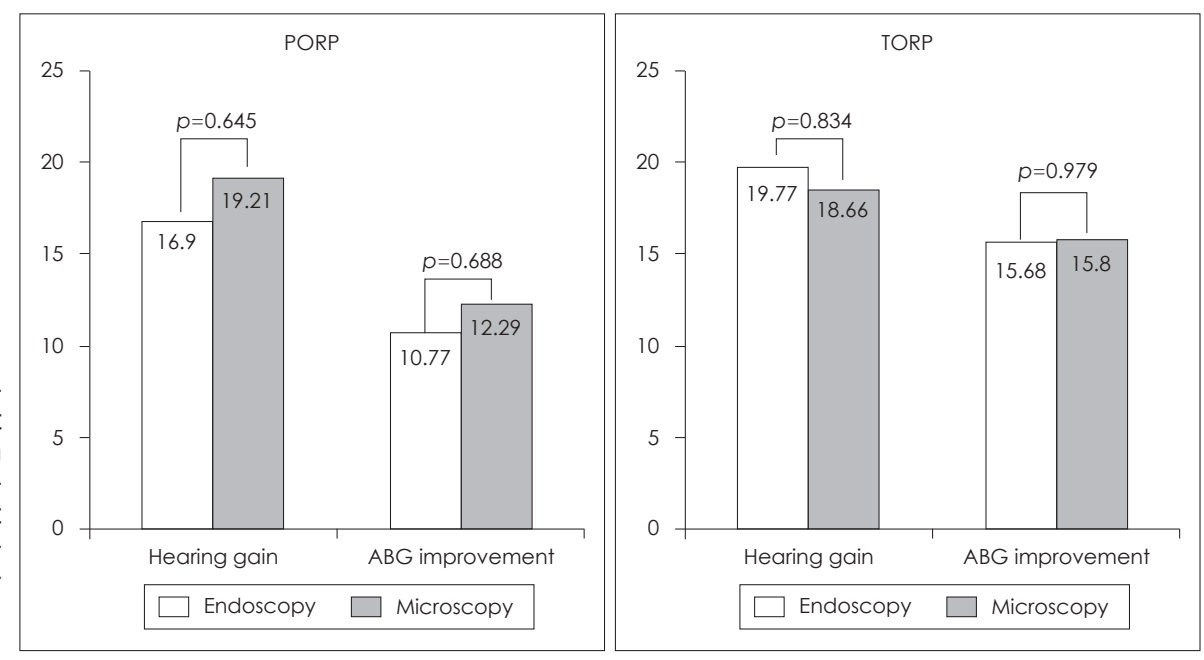
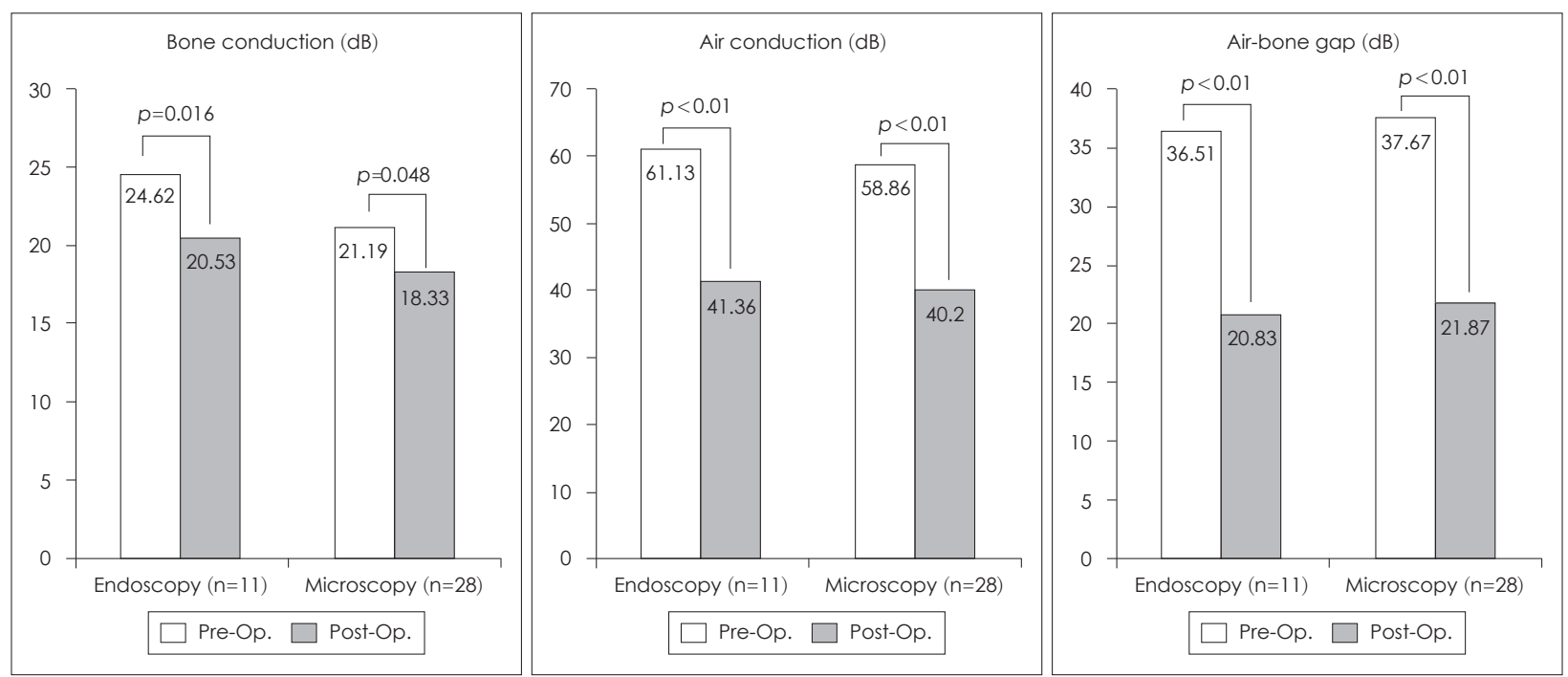

Fig. 5. Hearing results of TORP insertion. There was a significant difference in pre- and postoperative hearing result of TORP insertion within the two groups. TORP: total ossicular replacement prosthesis. 
Table 3. Overall hearing success rate ${ }^{7)}$

\begin{tabular}{lcccc}
\hline & Post-op. $\mathrm{ABG} \leq 20 \mathrm{~dB}$ & Hearing gain $\geq 15 \mathrm{~dB}$ & Post-op. $\mathrm{AC} \leq 30 \mathrm{~dB}$ & One of hearing success \\
\hline $\begin{array}{l}\text { Endoscopy } \\
\text { PORP }\end{array}$ & 10 & 7 & 4 & $12 / 14(85.7 \%)$ \\
TORP & 6 & 9 & 4 & $8 / 11(81.8 \%)$ \\
Microscopy & 19 & & & \\
PORP & 15 & 20 & 11 & $22 / 35(62.9 \%)$ \\
TORP & 16 & 9 & $18 / 28(64.3 \%)$ \\
\hline
\end{tabular}

Classification and hearing result reporting guideline in chronic otitis media surgery. ABG: air-bone gap, AC: air conduction, PORP: partial ossicular replacement prosthesis, TORP: total ossicular replacement prosthesis

\section{고 찰}

최근 내시경의 발달과 함께 의학의 여러 분야에서 수술에 대한 부담을 줄이고 치유기간을 단축시킬 수 있는 내시경 수 술이 각광받는 중이다. 이비인후과 영역에서는 비과적 수술 에서 부비동 내시경 수술의 발달로 수술적 패러다임의 변화 가 있었으나 이과적 수술에서의 내시경 적용은 수술현미경을 이용한 수술을 보완하거나 잔존 병변을 확인하는 수준으로 아직 초보단계에 있다.

내시경의 장점으로는 현미경과 달리 이개나 외이도의 굴곡 등에 시야가 방해받지 않고 밝고 선명한 상뿐만 아니라 넓은 시야를 확보할 수 있어 잘 보이지 않는 중이 내부의 확인이나 병변의 제거에 도움을 받을 수 있다. ${ }^{89}$ 최근에는 내이 및 내이 도의 병변에 대하여 유양돌기삭개술 없이 내시경을 이용한 수술적 접근법이 소개되기도 하였다. ${ }^{10)}$ 또한 고막륜 전체가 한 시야에 보이므로 고막이식술을 쉽게 행할 수 있으며 골 제 거 없이 수술현미경으로는 관찰이 어려운 후고실의 주요 구조 물을 잘 관찰할 수 있어서 시험적 고실개방술 및 이소골성형 술이 용이하다. ${ }^{11)}$ 본 연구에서도 내시경하 이소골성형술에서 수술현미경과 비교하여 수술 전후 기도 청력차 및 기도-골도 청력차에서 유의한 차이가 없는 반면에 내시경하에서 더 높은 수술 성공률을 보였다. 이는 내시경을 이용하여 선명하고 넓 은 시야에서 수술함으로써 정확한 위치에 인공소리뼈를 고정 하여 이탈을 최소화할 수 있기 때문이다. 하지만 이소골성형 술 성공률의 경우 환자요인이 결과에 큰 영향을 미치며 특히 이소골기형의 종류, 고막이나 이소골의 경화 정도 등은 주요한 요인이 되므로 추후 변수를 최대한 통제한 연구가 필요하다.

내시경 수술의 또 다른 장점은 최소침습적 수술이 가능하 다는 점이다. 내시경의 경우 후이개접근법과 비교하여 피부 및 연조직에 대한 절개 없이 외이도를 통해 수술이 가능하여 염증발생의 가능성이 적으며 흥터가 없다. 또한 본 연구에서 와 같이 수술시간이 단축되어 환자의 호응도가 높고 술 후 재 원기간 단축으로 인한 비용 절감 및 치유기간 감소의 효과가 있다. ${ }^{2)}$ 본 연구에서는 내시경을 이용한 수술 방법에서 수술
시간의 단축은 마취 방법에 의한 차이보다는 내시경을 이용 한 방법이 절개가 적고, 병변 부위를 쉽게 확인할 수 있어서 수술 술기를 빨리 결정하여 수술을 진행한 것이 영향을 준 것으로 생각된다. 술자의 경험상 성인 특히 외이도가 큰 경우 에서 수술이 쉬웠으며, 외이도가 작거나 소아의 경우 기구 조 작의 어려움이 있어 수술시간이 더 소요되는 경향이 있었다. 하지만 외이도에 내시경이 들어가는 경우에는 전 경우에서 수술이 가능하였다. 또한 내시경 수술 시 통증이 없고 절개 부위에 혈종이나 감염 가능성이 적어 술 후 어지럼증이 없다 면 하루나 이틀 후에 퇴원하여도 문제가 없었다.

내시경을 이용한 중이 수술의 가장 큰 문제점은 한 손은 내시경을 잡고 다른 한 손으로 수술을 진행하여야 한다는 점 이다. 이 방법은 수술현미경하에 양손을 사용하였던 의사에 게 이질감 및 어려움을 발생하여 거부감을 느끼게 한다. 하 지만 술자가 이에 적응을 하게 되면 크게 문제가 되지 않는 다. 특히 최근 20 년 전부터 수련을 받아온 전공의 및 전문의 들은 내시경을 사용한 코 수술에 대한 경험이 많아 내시경 을 이용한 귀 수술에 대한 적응이 그리 어렵지 않다. 또한 Khan과 $\mathrm{Parab}^{13,14)}$ 은 한 손 수술의 단점을 극복하기 위하여 내시경 holder를 이용한 양손 내시경 고실성형술을 소개하 기도 하였다.

내시경 수술의 또 다른 단점은 내시경 수술 시 유양동 내에 병변이 있으면 내시경만을 가지고 수술을 시행하기 어렵다는 점이다. 하지만 유양돌기삭개술과 함께 내시경을 이용한 경 우 외이도 후벽 보존 확률 및 중이 내 병변의 일괄 절제 가능 성이 증가한다. Rehl 등히은 카데바 연구에서 폐쇄동유양돌 기절제술과 함께 내시경을 이용한 경우 개방동유양돌기절제 술과 비교하여 고실동(sinus tympani)에 대하여 더 좋은 시야 를 보여주었으며 외측 상고실(lateral epitympanum), 등골 뒷 다리(posterior crus of stapes), 난원창(round window niche) 의 시야에는 큰 차이가 없음을 보고하였다.

또한 내시경을 이용한 중이 수술에서 내시경 끝에 발생한 열에 의한 중이 내 손상가능성은 논쟁이 되고 있다. ${ }^{16)}$ Shah 등 ${ }^{17)}$ 은 카데바 연구에서 내시경에서 방출된 열에 의해 중이 
내 체온이 상승할 수 있고 동물연구에서 중이 내 체온상승은 auditory brainstem response 변화를 유도할 수 있음을 보고 하였다. 본 연구에서 내시경 수술 시 일시적인 어지럼증을 호 소하는 경우는 있었으나 중이 내 점막 화상이나 감각신경성 난청 등의 신경학적 이상은 보이지 않았다. 내시경 수술 시 수 술시간이 짧고 흡입관을 통하여 열이 배출될 수 있으며 혈액 등에 의해 시야가 흐려진 경우 생리식염수로 세척하거나 내시 경을 알코올이 묻은 거즈로 닦는 등의 행위로 인하여 수술 시 내시경에 의한 생리학적 영향은 미미한 것으로 사료된다. ${ }^{17)}$

술자의 경험상 0 도 내시경의 경우 고실 안쪽으로의 접근 없 이 외이도의 고실륜 바깥쪽에 렌즈의 끝이 위치한 상태로 수 술이 이루어질 수 있었다. 비록 외이도에 내시경이 있더라도 렌즈에서 시야가 확대되어 고실 내 감춰진 곳을 관찰하는 데 용이하기 때문에 0도 내시경 단독으로 대부분의 수술이 가능 하였다. 하지만 0 도 내시경으로도 시야가 불분명할 시 30 도 내 시경 사용이 필요하며 이 경우에는 고실 내로 렌즈의 삽입 가 능성이 있어 의인성 손상을 주의해야 한다. 또한 렌즈에 이 물이 묻는 것을 최소화하기 위하여 외이도 침윤마취 시 수포 가 생기지 않도록 주의해야 하며 외이도 귀털을 미리 제거하 는 것도 유용한 방법이다. 출혈의 경우 대부분 외이도의 피 부절개부위에서 발생하므로 외이도마취 시행 후 5 10분 후 에 절개를 시작하는게 도움이 되며 에피네프린이 함유된 솜 과 함께 피판을 올리면 출혈을 줄일 수 있다.

결론적으로 내시경을 이용한 중이 수술은 기존의 수술 방 법과 비교하여 특별한 부작용이 없는 안전한 수술법이다. 특 히 간단한 고실성형술이나 소아에서의 선천성 진주종 제거 수술, 전음성 또는 혼합성 난청에서 시험적 고실개방술 및 이 소골성형술에 있어서 현미경을 이용한 중이 수술에 비하여 덜 침습적인 접근을 통하여 병변의 제거 및 재건이 가능하며 수술 결과 또한 기존 방법과 비교하여 비슷하거나 더 나은 결과를 보였다.

\section{REFERENCES}

1) Huang TY, Ho KY, Wang LF, Chien CY, Wang HM. A comparative study of endoscopic and microscopic approach type 1 tympanoplasty for simple chronic otitis media. J Int Adv Otol 2016;12(1):28-31.

2) Nassif N, Berlucchi M, Redaelli de Zinis LO. Tympanic membrane perforation in children: endoscopic type I tympanoplasty, a newly technique, is it worthwhile? Int J Pediatr Otorhinolaryngol 2015; 79(11):1860-4.

3) Özgür A, Dursun E, Erdivanli ÖÇ, Coşkun ZÖ, Terzi S, Emiroğlu $\mathrm{G}$, et al. Endoscopic cartilage tympanoplasty in chronic otitis media. J Laryngol Otol 2015;129(11):1073-7.

4) Hiraumi H, Yamamoto N, Sakamoto T, Ito J. A minimally invasive approach for cochlear implantation using a microendoscope. Eur Arch Otorhinolaryngol 2013;270(2):477-81.

5) Kozin ED, Gulati S, Kaplan AB, Lehmann AE, Remenschneider AK, Landegger LD, et al. Systematic review of outcomes following observational and operative endoscopic middle ear surgery. Laryngoscope 2015;125(5):1205-14.

6) Sohn SJ, Park CM, Choe SH, Choi YS, Kwon SW. Endoscopic tympanoplasty. Korean J Otolaryngol-Head Neck Surg 2000;43(6): 598-603.

7) Kim HJ. Classification and hearing result reporting guideline in chronic otitis media surgery. Korean J Otolaryngol-Head Neck Surg 2006;49(1):2-6.

8) Badr-el-Dine M. Value of ear endoscopy in cholesteatoma surgery. Otol Neurotol 2002;23(5):631-5.

9) Thomassin JM, Korchia D, Doris JM. Endoscopic-guided otosurgery in the prevention of residual cholesteatomas. Laryngoscope 1993; 103(8):939-43.

10) Marchioni D, Alicandri-Ciufelli M, Mattioli F, Nogeira JF, Tarabichi M, Villari D, et al. From external to internal auditory canal: surgical anatomy by an exclusive endoscopic approach. Eur Arch Otorhinolaryngol 2013;270(4):1267-75.

11) Kojima H, Komori M, Chikazawa S, Yaguchi Y, Yamamoto K, Chujo $\mathrm{K}$, et al. Comparison between endoscopic and microscopic stapes surgery. Laryngoscope 2014;124(1):266-71.

12) Choi N, Noh Y, Park W, Lee JJ, Yook S, Choi JE, et al. Comparison of endoscopic tympanoplasty to microscopic tympanoplasty. Clin Exp Otorhinolaryngol 2016 Jun 18 [Epub]. https://doi.org/10.21053/ ceo.2016.00080.

13) Khan MM, Parab SR. Endoscopic cartilage tympanoplasty: a twohanded technique using an endoscope holder. Laryngoscope 2016; 126(8):1893-8.

14) Khan MM, Parab SR. Novel concept of attaching endoscope holder to microscope for two handed endoscopic tympanoplasty. Indian J Otolaryngol Head Neck Surg 2016;68(2):230-40.

15) Rehl RM, Oliaei S, Ziai K, Mahboubi H, Djalilian HR. Tympanomastoidectomy with otoendoscopy. Ear Nose Throat J 2012;91(12):527-32.

16) Kozin ED, Lehmann A, Carter M, Hight E, Cohen M, Nakajima $\mathrm{HH}$, et al. Thermal effects of endoscopy in a human temporal bone model: implications for endoscopic ear surgery. Laryngoscope 2014; 124(8):E332-9.

17) Shah PV, Kozin ED, Remenschneider AK, Dedmon MM, Nakajima $\mathrm{HH}$, Cohen MS, et al. Prolonged radiant exposure of the middle ear during transcanal endoscopic ear surgery. Otolaryngol Head Neck Surg 2015;153(1):102-4. 